Int. J. Electrochem. Sci., 13 (2018) $7612-7628$

International Journal of

ELECTROCHEMICAL

SCIENCE

www.electrochemsci.org

\title{
Corrosion inhibition of 6061Al-Si alloy by using Metronidazole in 0.1M HCl Medium
}

\author{
A. S. Fouda ${ }^{1 *}$, F.I. Al desoky ${ }^{2}$, W.T. Elbehairy ${ }^{1}$, A.Elmohamad ${ }^{1}$ \\ ${ }^{1}$ Department of Chemistry, Faculty of Science, El-Mansoura University, El-Mansoura-35516, Egypt, \\ ${ }^{2}$ Department of Chemistry, Faculty of Science, Port Said University, Egypt \\ *E-mail: asfouda@hotmail.com, asfouda@mans.edu.eg
}

doi: $10.20964 / 2018.08 .31$

Received: 12 March 2018 / Accepted: 10 May 2018 / Published: 5 July 2018

The corrosion behavior of $6061 \mathrm{Al}-\mathrm{Si}$ alloy in $0.1 \mathrm{M} \mathrm{HCl}$ in the being present of Metronidazole(MNZ) compound has been observed using open circuit potential(OPC), AC impedance (EIS), Tafel diagrams, electrochemical frequency modulation (EFM)and weight reduction (WR) methods. The protective efficacy (IE) rises by raising the Metronidazole extent (MNZ) and diminished by raising the temperature. Tafel diagram has shown that the Metronidazole acts as a mixed-kind inhibitor. MNZ adsorption on the alloy surface was obeying Temkin isotherm. The surface analysis of Al alloy was performed by scanning electron microscope (SEM), AFM (atomic force microscopy) and Fourier transform infrared spectra (FT-IR).

Keywords: Corrosion, Adsorption, Al alloy, HCl, SEM, AFM, FTIR

\section{FULL TEXT}

(C) 2018 The Authors. Published by ESG (www.electrochemsci.org). This article is an open access article distributed under the terms and conditions of the Creative Commons Attribution license (http://creativecommons.org/licenses/by/4.0/). 